\title{
Meningitis Caused by Neisseria meningitides Serogroup B in a Newborn in China
}

\author{
Jinjing Zhang, Yajuan Wang*, Jie Luo, Yijun Ding and Fang Shao \\ Beijing Children's Hospital, Capital Medical University, MOE Key Laboratory of Major Diseases in Children, Beijing 100045, People's Republic of China
}

Received: September 16, 2016; Accepted: October 21, 2016; Published: October 25, 2016

*Corresponding author: Yajuan Wang, Beijing Children's Hospital, Capital Medical University, MOE Key Laboratory of Major Diseases in Children, Beijing 100045, People's Republic of China.E-mail: cxswyj@vip.sina.com

\begin{abstract}
Neisseria meningitides is one of the major causes of meningitis in children, but it is rarely found during the neonatal period. Here, we described a neonate with meningococcal sepsis and meningitis who was admitted to the hospital on postnatal day 17 , and we reviewed the literature of a 99-year period as well, in order to emphasis on the notice of uncommon pathogens in neonates.
\end{abstract}

Key words: Neisseria meningitidis; Meningitis; New born

\section{Introduction}

Neonatal bacterial meningitis is a major disease that results in death and significant morbidity worldwide. It is characterized by an infection of the Central Nervous System (CNS) and caused by a limited range of bacteria. Of all the cases [1,2], Group B Streptococcus (GBS) and E. coli are the leading pathogens. However, Klebsiella, Enterobacter, Citrobacter and Serratia species, Streptococcus pneumoniae, Listeria monocytogenes, Staphylococci aureus and coagulase-negative Staphylococci can also be diagnosed in some cases, but Neisseria meningitidis ( $N$. meningitides) is not common in neonatal bacterial meningitis. There have been 48 cases of Neonatal Meningococcal Meningitis (NMM) described since the first case reported in 1916 [3]. The incidence of NMM ranges from 0.8 to 1.3 per 100,000 in USA as reported. The spectrum of disease ranges from mild fever to fulminant septic shock, purpura fulminans, coma, and death.

For the review of previously reported cases [3-16], we defined cases of meningitis associated with $N$. meningitidis when cases had microbiologic evidence of $N$. meningitidis consisting of at least one of: a positive culture of blood and/or Cerebrospinal Fluid (CSF) and/or positive Polymerase Chain Reaction (PCR) for meningococcal DNA.

Reported cases of meningitis caused by $N$. meningitidis and meeting the case definition were identified through a MEDLINE search of published articles. Clinical features, microbiologic results, treatments and outcome were recorded.

\section{Case report}

Our case, a 17-day-old male baby, was born by cesarean section at 41 weeks' gestation with a birth weight of $3545 \mathrm{~g}$. During pregnancy, his mother was healthy. The natal history was unremarkable. Apgar score was all 10 at 1, 5 and 10 minute. He was breastfed. The neonate was admitted to the hospital due to a one-day history of fever, dispirited, choking, without convulsion, diarrhea or rash. Blood routine: White Blood Cell (WBC) $5.49 \times 10^{9} /$ L, neutrophilic granulocyte $66.1 \%$, lymphocytes 29.3\%, hemoglobin, platelets and C-reactive protein (CRP) were normal. X-ray of the chest was unremarkable. No special findings except the total bilirubin, direct and indirect bilirubin were slightly elevated. No exposure to cold patients.

On physical Examination: temperature was $38.5^{\circ} \mathrm{C}$, weight was 3.48 kilogram, height was 53 centimeters, head circumference was 34 centimeters, respiratory rate was 50 times per minute, heart rate was 182 beats per minute, blood pressure was 84/ $56 \mathrm{mmHg}$. He was conscious and very irritable on handling. Face and trunk were lightly yellow, no rash or petechia. Anterior fontanelle was flat, pupillary reflex was sensitive. The results of cardiovascular and respiratory examinations were normal. The patient did not exhibit organomegaly or eruptions. The capillary filling time was $2 \mathrm{~s}$. Sucking reflex and rooting reflex were normal, grasping and Moro reflex were weak.

Investigations demonstrated the results of a complete blood count and serum biochemical analysis did not reveal any abnormalities. The patient's C-reactive protein level was normal ( $<8 \mathrm{mg} / \mathrm{L}$ ). The CSF profile was abnormal: white blood cell count $760 \times 10^{6} / \mathrm{L}$, polykaryocytes $82 \%$, monocytes $18 \%$, glucose 0.22 mmol/ L, chloride $111 \mathrm{mmol} / \mathrm{L}$, and protein $2413 \mathrm{mg} / \mathrm{L}$. Blood culture samples were obtained. CT scan of the head showed some low density area in the bilateral cerebrum white matter and anterior part of basal ganglia. Cranial and abdominal ultrasound investigations done were evaluated as normal. Nasopharyngeal carriage and maternal vaginal carriage were found to be negative.

The patient was diagnosed with sepsis and meningitis based on the clinical and laboratory findings. Penicillin $(800,000 \mathrm{U} /$ $\mathrm{kg}$ of body weight/ day) and cefotaxime $(100 \mathrm{mg} / \mathrm{kg} /$ day $)$ with intravenous (IV) were administered. A total of $1 \mathrm{~g} / \mathrm{kg}$ of intravenous immunoglobulin was administered.

The blood culture subsequently grew N. meningitidis, and drug sensitive test indicated it was sensitive to Azithromycin, 
Meropenem and Ceftriaxone. A CSF culture was sterile. Real-time -PCR of the CSF proved the same causative agent as blood culture. Classification of the bacteria was confirmed by SunBioStar TM Multiplex Real-time PCR Detection Kit. It indicated that caused pathogen was $N$. meningitides, serogroup B.

Continued therapy with Penicillin and Cefotaxime were preceded due to the drug allergy testing. At the same time, the infant turned better both in clinical symptoms and CSF parameters.

Recheck CSF on the $4^{\text {th }}, 9^{\text {th }}, 15^{\text {th }}, 19^{\text {th }}, 25^{\text {th }}, 32^{\text {th }}, 37^{\text {th }}$ day prompted protein and WBC count of CSF decreased gradually (Figure 1). Recheck blood routine (Figure 2) indicated the infection was under control gradually. On the $33^{\text {rd }}$ hospital day, crianal Magnetic Resonace Imaging(MRI) showed long T1 and long T2 signal under the left skull, no expansion of the ventricular system, no shift of midline structures. After 37 days therapy, the baby was well response, and he was discharged from the hospital.

The infant was followed up at 3-month, 6-month, 9-month, and 1-year. He had made normal developmental progress. He could raised his head at 3-month, sit steady at 5.5-month Intelligence test (Gesell) at 1 year was normal at his age.

We identified 37 previous cases of $N$. meningitidis meningitis reported in English literature (included our case) between 1916 and 2014 [3-16]. The clinical features, microbiologic results, sero-group outcomes and complications of the 37 cases were summarized in the table (Table 1). The initial symptoms of the cases were generally insignificant. Fever was reported to occur in $46 \%$ of cases $(n=17)$, and petechiae in $32 \%(n=12)$. A definitive

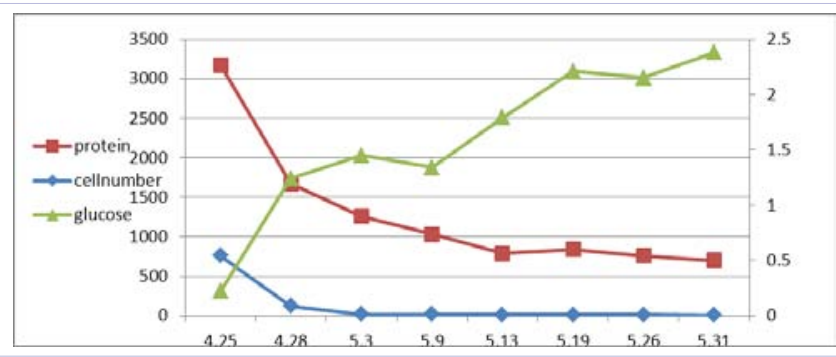

Figure 1: CSF data

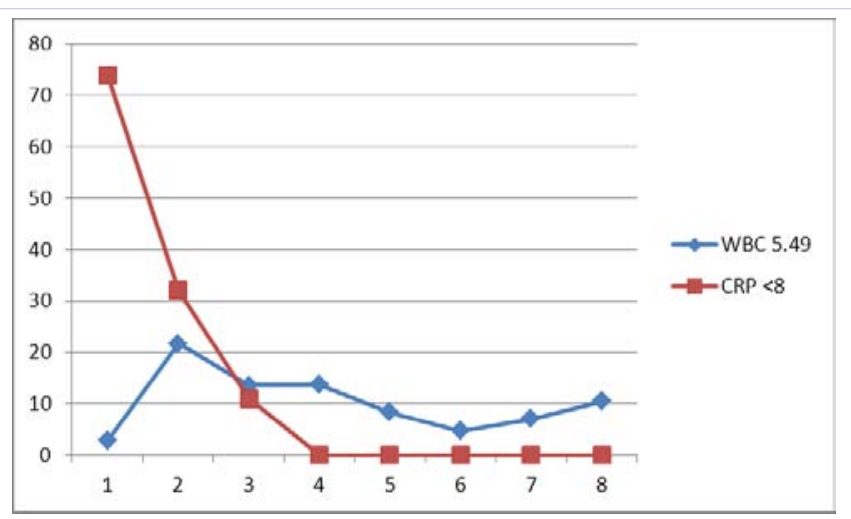

Figure 2: Changes of WBC and CRP diagnosis was successfully made after isolation from blood and CSF cultures. The microorganism was detected in 59\% $(n=22)$ of cases by blood culture, in $70 \%(n=26)$ of cases by CSF culture, and in $35 \%$ of cases $(n=13)$ by both blood and CSF cultures. $59 \%(n=22)$ of them got serotypes, $3 \%(n=1)$ was serogroup $A$, $32 \%(n=12)$ were serogroup $B, 16 \%$ were serogroup $C(n=6)$, $5 \%$ were serogroup W135 (n=2), 3\% (n=1) was serogroup Y. Serogroup B was found the most common serotype.

\section{Discussion}

The common pathogens caused neonatal bacterial meningitis were E. coli, GBS, Listeria monocytogenes [1,2]. Although $N$. meningitidis is a frequent cause of bacterial meningitis and sepsis during childhood, it is rare and causes a high rate of mortality during the neonatal period [17]. The incidence of meningococcal infection in the general population is $0.8-1$ per 100,000 in the United States [18], and 10 to 25 cases per 100,000 persons in the developing countries [19]. Data from the Bacterial Core Surveillance Program indicated an annual incidence of 9 per 100,000 newborn infants [20].

$N$. meningitidis is a gram-negative $\beta$-proteobacterium and member of the bacterial family Neisseriaceae. It is not only a common bacterial commensal of the human upper respiratory tract (nasopharynx) but also an important and devastating human pathogen. Acquisition of meningococci through very close contact with respiratory secretions or saliva can be transient, lead to colonisation (carriage), or result in invasive disease. Meningitis is the most common clinical presentation of invasive meningococcal disease. Usual manifestations were fever, rash, a meningeal signs, and altered mental status, but these presentations were atypical in neonates, the boy in the present case got no rash through the process. Early diagnosis was difficult to make in new-born babies. Here, we described a neonate with meningococcal sepsis who was admitted to the hospital on postnatal day 17 with a fever, dispirited, and choking.

For therapy, early antibiotic treatment should be the primary goal, since effective antibiotics immediately stop the proliferation of $N$. meningitides [21]. Recommended empirical antibiotics were Ampicillin (50-100 mg/ kg every $6 \mathrm{~h}$ ) plus gentamicin $(2.5 \mathrm{mg} /$ kg every $8 \mathrm{~h}$ ), or cefotaxime ( $50 \mathrm{mg} / \mathrm{kg}$ every 6-8 h) can be used in the setting of suspected Gram-negative bacilli [22]. Proper drugs should be given right after the causative agent was definite. Duration of antimicrobial therapy for bacterial meningitis caused by $N$. meningitis was 7 days [23]. Intravenous antimicrobial therapy is recommended for the duration of treatment to ensure that adequate CSF concentrations. In neonatal, duration of antibiotics was 2 weeks at least. Duration of antibiotics we reported the case was 37 days, because the WBC count of CSF dropped to normal until 2 weeks' therapy, glucose concentration rose to normal until 3 weeks' therapy, and subdural effusion was found on the 33th day, all these factors contributed to the "longterm" antimicrobial therapy.

There were 37 cases reported in English literature (included our case) [1-14], 22 of them got serotypes. Serogroup B was found the most common serotype, so did our case. The vaccination of $N$. 


\begin{tabular}{|c|c|c|c|c|c|c|c|c|c|c|c|c|c|}
\hline \multicolumn{2}{|l|}{ Age } & \multicolumn{2}{|l|}{ Fever } & \multicolumn{2}{|l|}{ petechiae } & \multicolumn{2}{|c|}{ blood culture } & \multicolumn{2}{|c|}{ CSF culture } & \multicolumn{2}{|c|}{ Sero-group } & \multicolumn{2}{|l|}{ Outcome } \\
\hline \multirow{4}{*}{$<7 d$} & \multirow{4}{*}{$\begin{array}{c}35 \% \\
(n=13)\end{array}$} & \multirow{2}{*}{ With } & \multirow{2}{*}{$\begin{array}{c}46 \% \\
(n=17)\end{array}$} & \multirow[t]{2}{*}{ With } & \multirow{2}{*}{$\begin{array}{c}32 \% \\
(n=12)\end{array}$} & \multirow[t]{2}{*}{ Positive } & \multirow[t]{2}{*}{$\begin{array}{c}59 \% \\
(n=22)\end{array}$} & \multirow[t]{2}{*}{ Positive } & \multirow[t]{2}{*}{$\begin{array}{c}70 \% \\
(n=26)\end{array}$} & A & $\begin{array}{c}3 \% \\
(\mathrm{n}=1)\end{array}$ & \multirow{2}{*}{ Survived } & \multirow{2}{*}{$\begin{array}{c}57 \% \\
(n=21)\end{array}$} \\
\hline & & & & & & & & & & B & $\begin{array}{c}32 \% \\
(n=12)\end{array}$ & & \\
\hline & & \multirow[b]{2}{*}{ Without } & \multirow[b]{2}{*}{$\begin{array}{c}49 \% \\
(n=18)\end{array}$} & \multirow[b]{2}{*}{ Without } & \multirow[b]{2}{*}{$\begin{array}{c}65 \% \\
(n=24)\end{array}$} & \multirow[b]{2}{*}{ Negative } & \multirow[b]{2}{*}{$\begin{array}{c}38 \% \\
(n=14)\end{array}$} & \multirow[b]{2}{*}{ Negative } & \multirow[b]{2}{*}{$\begin{array}{c}27 \% \\
(n=10)\end{array}$} & $\mathrm{C}$ & $\begin{array}{c}16 \% \\
(n=6)\end{array}$ & \multirow[b]{2}{*}{ Died } & \multirow{2}{*}{$\begin{array}{c}32 \% \\
(\mathrm{n}=12)\end{array}$} \\
\hline & & & & & & & & & & W135 & $\begin{array}{c}5 \% \\
(n=2)\end{array}$ & & \\
\hline \multirow[t]{2}{*}{$\geq 7 d$} & \multirow{2}{*}{$\begin{array}{c}65 \% \\
(\mathrm{n}=24)\end{array}$} & \multirow[t]{2}{*}{ Unknown } & \multirow{2}{*}{$\begin{array}{c}5 \% \\
(n=2)\end{array}$} & \multirow[t]{2}{*}{ Unknown } & \multirow{2}{*}{$\begin{array}{c}3 \% \\
(n=1)\end{array}$} & \multirow[t]{2}{*}{ Unknown } & \multirow{2}{*}{$\begin{array}{c}3 \% \\
(n=1)\end{array}$} & \multirow[t]{2}{*}{ Unknown } & \multirow{2}{*}{$\begin{array}{c}3 \% \\
(n=1)\end{array}$} & $\mathrm{Y}$ & $\begin{array}{c}3 \% \\
(n=1)\end{array}$ & Unknown & $11 \%$ \\
\hline & & & & & & & & & & $\begin{array}{c}\text { not } \\
\text { classified }\end{array}$ & $\begin{array}{c}41 \% \\
(n=15)\end{array}$ & & \\
\hline
\end{tabular}

meningitidis covers serogroup A and $\mathrm{C}$ in China and this may be the reason why serogroup $\mathrm{B}$ is more common recently.

Of the 37 cases, 21 were survived, 3 of them with hydrocephalus, and 12 died. In general, the outcome varies as gestation, prolonged labor, effective antibiotics and other factors, the mortality is pretty high, and it is an emergent infection that needs immediate treatment.

\section{Conclusion}

Although $N$. meningitidis is rare, $N$. meningitidis should be considered even if there are no specific clinical findings. Early, fast, and appropriate treatments remain keys in outcome.

\section{References}

1. $\mathrm{Ku} \mathrm{LC}$, Boggess KA, Cohen-Wolkowiez M. Bacterial meningitis in infants. Clin Perinatol. 2015;42(1):29-45, vii-viii. doi: 10.1016/j. clp.2014.10.004.

2. Paul T heath, Ifeanyichukwu O. Okike. Neonatal bacterial meningitis: an update. Paediatrics and child health. 2010;20(11):526-530.

3. Kiray Baş E, Bülbül A, Cömert S, Uslu S, Arslan S, Nuhoglu A. Neonatal Infection with Neisseria meningitidis: Analysis of a 97-Year Period Plus Case Study. J Clin Microbiol. 2014;52(9):3478-82. doi: 10.1128/ JCM.01000-14.

4. Jones RN, Slepack J, Eades A. Fatal neonatal meningococcal meningitis. Association with maternal cervical-vaginal colonization. JAMA. 1976;236(23):2652-3.

5. Schaberg MJ. Neonatal meningococcal meningitis. JAMA 1977;237(22):2381.

6. Clegg HW, Todres ID, Moylan FM, Keim DE, Shannon DC. Fulminant neonatal meningococcemia. Am J Dis Child. 1980;134(4):354-5.

7. Embree J, Law BJ, Williams T, Edye-Mazowita G. Early onset neonatal sepsis due to Neisseria meningitidis W135. Pediatr Infect Dis J. 1987;6(3):299-300.

8. Chiu $\mathrm{CH}$, Lin TY, Yang $\mathrm{PH}$, Hwang MS. Neonatal meningococcal meningitis: report of two cases. Zhonghua Min Guo Xiao Er Ke Yi Xue Hui Za Zhi. 1994;35(6):542-5.

9. Arango CA, Rathore $\mathrm{MH}$. Neonatal meningococcal meningitis: case reports and review of literature. Pediatr Infect Dis J. 1996;15(12):1134-
10. Katier N, Traen M, De Dooy J, Geyskens L, Mahieu L. Neonatal purpura due to Neisseria meningitidis serogroup C infection. Eur J Pediatr. 2003;162(4):283-4

11. Falcão MC, Andrade SB, Ceccon ME, Costa Vaz FA. Neonatal sepsis and meningitis caused by Neisseria meningitidis: a case report. Rev Inst Med Trop Sao Paulo. 2007;49(3):191-4.

12. Tinsa F, Jallouli M, Ben Lassouad M, Smaoui H, Brini I, Bousseta K, et al. Neonatal meningitis by Neisseria meningitidis B. Tunis Med. 2008;86(11):1014-5.

13. Bosman M,Archary M, MahabeerP, BobatRA. Earlyonsetmeningococcal meningitis. South Afr J Epidemiol Infect. 2013;28(3):177-179.

14. Smith A, Zehetner A. Early onset neonatal serogroup B meningococcal meningitis and septicaemia. J Paediatr Child Health. 2013;49(2):158. doi: 10.1111/jpc.12079.

15. Shah S, Gross JR, Stewart CT. A case report of meningococcal disease in a neonate. WMJ. 2013;112(1):28-30

16. Devi U, Mahanta J. Neonatal meningitis due to Neisseria meningitidis serogroup Y. Indian Pediatr. 2014;51(9):757.

17. Klinger G, Chin CN, Beyene J, Perlman M. Predicting the outcome of neonatal bacterial meningitis. Pediatrics. 2000;106(3):477-82.

18. Harrison LH. Preventing meningococcal infection in college students. Clin Infect Dis. 2000;30(4):648-51.

19. Harrison LH, Trotter CL, Ramsay ME. Global epidemiology of meningococcal disease. Vaccine. 2009;27 Suppl 2:B51-63. doi: 10.1016/j.vaccine.2009.04.063

20.Shepard CW, Rosenstein NE, Fischer M. Neonatal meningococcal disease in the United States 1990 to 1999 . Pediatr Infect Dis J. 2003;22(5):418-22

21. Tunkel AR, Hartman BJ, Kaplan SL, Kaufman BA, Roos KL, Scheld WM, et al. Practice Guidelines for the management of Bacterial Meningitis. Clin Infect Dis. 2004;39(9):1267-84.

22.Stephens DS, Greenwood B, Brandtzaeg P. Epidemic meningitis, meningococcaemia, and Neisseria meningitides. Lancet. 2007;369(9580):2196-210.

23. Kim KS. Acute bacterial meningitis in infants and children. Lancet Infect Dis. 2010;10(1):32-42. doi: 10.1016/S1473-3099(09)70306-8. 